\title{
Four archetypes of process improvement: a Q-methodological study
}

\begin{abstract}
This paper explores the process improvement approaches of organisations. It seeks to identify process redesign principles and the combinations of these principles that are used successfully in industry. We use Q-methodology to explore the viewpoints of a range of highly-experienced process experts about the success of 16 improvement practices. Qmethodology enables the examination of the similarities and differences in the success of the improvement principles used by organisations in order to inform archetypes of process improvement. Overall, our findings suggest that process improvement is determined through the application of two foundational principles combined with one of four archetypes. 'Remove non-value-adding tasks' and 're-sequence tasks' are described as foundational principles of process improvement, whilst outsourcing needs to be approached with caution. Furthermore, we articulate four distinctive archetypes comprising unique configurations of improvement principles that can be used to redesign operational processes. Based on this evidence we propose a typology of process improvement. This work suggests that rather than adopting generic improvement frameworks, managers should consult the typology to determine the archetype in closest proximity to their specific requirements. This study has several limitations including the small number of items populating the concourse and the fact that implementation problems are not taken into account.
\end{abstract}

Keywords: Operations management, process innovation, process improvement and redesign, Q-methodology

\section{Introduction}

The pursuit of increased organisational competitiveness has been approached through a variety of process-focused thematic initiatives over the last two decades. Firms engaged in improvement activities attempt to impact the performance of their operational processes. The importance of the process paradigm is pointed out by Grover and Kettinger $(2000,16)$ : "process thinking has become mainstream", and by Fowler $(2003,138)$ : "the issue of process has now achieved equal status with strategy and organisation theory as a concern for debate and analysis at the highest level within organisations". Moreover, the framework articulated by Smart et al. (2009) emphasises the need for a process mindset to realise improvements. Business process management (BPM) and other process-focused improvement philosophies have been equally embraced by manufacturing and service organisations. Since products and services are produced and delivered through operational processes, a key determinant of performance, and subsequent competitiveness, is the appropriate design and improvement of these processes (Lu and Botha 2006).

Process design decisions relate to the specifications of resources and their allocation to specific tasks, the sequential dependency of tasks and the appropriate location for task execution (Hammer 2007). Process design includes the configuration of completely new processes and the improvement of existing processes; the latter being the most common and 
practical approach (e.g. see Aldowaisan and Gaafar 1999). Establishing and maintaining a process configuration that produces effective outputs drives customer satisfaction and loyalty over time (Johnston and Clark 2005) and, therefore, leads to increased profitability (Heskett et al. 1994). A longitudinal case study in the banking industry, for example, shows that process management supports enhanced service quality and increased customer satisfaction (Maddern et al. 2007). Overall, empirical research has vastly supported the relationships between process design, customer satisfaction, and profitability (Ittner and Larcker 1998).

As competition heightens, organisations endeavour to continually improve their operational processes to achieve and sustain superior levels of performance. Rigby and Bilodeau (2005) report the results of a large-scale survey of senior business managers showing that process redesign remains as popular as it was 20 years ago. A survey of chief operating officers shows that they consider process improvement to be the number one business priority (Auringer 2009). Similarly, Voss and Huxham (2004) point out that it is difficult to identify a large organisation that does not invest in the design and improvement of its operational processes. Although the ongoing improvement of processes remains a key priority for most organisations, industry estimates suggest that up to $70 \%$ of redesign initiatives fail to deliver the expected improvements in operational performance (Clement 2012).

The importance of process improvement for the practitioner community contrasts with the limited theoretical advances achieved in the academic literature. Hill et al. $(2002,197)$ note that "a review of the reengineering and service process design literatures finds thousands of 'how-to' managerial articles and company testimonials, but surprisingly few articles published in academic journals". Whilst scholars have recently expended significant efforts to develop methodologies and roadmaps for conducting process improvement projects (Cottyn et al. 2011; Dassisti 2010; Aurich et al. 2009; Juan and Ou-Yang 2004), few empirical studies focus on the practices of process improvement used by organisations (Reijers and Liman Mansar 2005; Ayhan et al. 2013). As a result, this organisational activity remains more art than science (Liman Mansar and Reijers 2007). Notably, the limited empirical evidence examining what improvement practices been applied with success or not in industry has hampered theoretical development. A comprehensive review of the BPM and operations management $(\mathrm{OM})$ literatures on process design highlight the need for further research in this area (Ponsignon et al. 2012). Similarly, Hill et al. (2002) encourage the development of new frameworks to classify process improvement practices. In summary, there appears to be incongruence between the priorities of researchers and those of practitioners in the process improvement domain, a problem previously reported (Slack et al. 2004). A paucity of theory informing process improvement principles and their applicability across organisations therefore necessitates the empirical exploration of this phenomenon.

Against this background, this article aims to facilitate the development of a theory of process improvement. First, we set out to determine which improvement principles are more successful relative to other principles. We define an improvement principle as a general rule that organisations can apply to improve process performance. Our first research question is: What are the most and least successful principles of process improvement? Second, in addition to a focus on individual improvement principles, this article aims to identify distinctive archetypes of process improvement. An archetype refers to a pattern of 
improvement principles which should be applied when redesigning operational processes. Our definition of archetype is consistent with the conceptualisation of Greenwood and Hinings (1993, p.1052) who refer to an organisational archetype as an overall "set of structures and systems that reflect a single interpretive scheme". We formulate our second research question as: What are the major archetypes of process improvement?

The remainder of the paper is organised into five sections. Section two reviews the existing literature on process design and improvement. Section three discusses the rationale for the use of Q-Methodology as a research approach and provides a description of the research design. Section four presents the research findings. Section five describes the implications of this research for theory and practice, presents future research opportunities and shows the research limitations. Section six concludes the paper.

\section{Background literature}

Scholars have recognised the importance of establishing process improvement principles and that theory in this area is currently underdeveloped. The BPM literature is largely prescriptive (Loch 1998), with authors providing generic redesign principles described as universally applicable to organisations (Reijers and Liman Mansar 2005). These principles are primarily developed out of best practices of process redesign that were successfully applied in leading organisations (Davenport 1993; Harrington 1991; Hammer and Champy 1993; Madison 2005). According to Liman Mansar et al. (2008, 3248), a redesign best practice is "a general heuristic derived from earlier successful encounters to improve process performance". More generally, a best practice is seen as a solution to a problem faced by many organisations and that has produced superior results (Ungan 2005). Process improvement principles derived from best practices are assumed to be "universal in the sense that they are applicable within the context of any business process" (Reijers and Liman Mansar 2005, 295). This view promotes the general application of best practices because it assumes that they are always effective (Zairi 1997). A recent survey seems to corroborate this position by finding that redesign best practices are extensively used by practitioners in various industries, such as business planning, healthcare, manufacturing and software development (Liman Mansar and Reijers 2007). This discussion suggests that best practices of redesign are effective in virtually all operational systems and that organisations may employ a similar set of practices to achieve process improvements.

The alleged universality of process redesign is slightly inconsistent with several empirical studies that find that OM best practices are not uniformly successful (Ketokivi and Schroeder 2004; Sousa and da Silveira 2010). For instance, Wiengarten et al. (2013) find that TQM practices are more effective in highly-innovative organisations. In keeping with these research findings, Reijers and Liman Mansar (2005) acknowledge that the direct application of generic redesign principles is unlikely to automatically result in sustained performance improvements. They argue that more research is needed in order to determine the improvement principles organisations should use to redesign their operational processes. In particular, two related issues need to be addressed to develop a theory of process improvement and to inform practice.

First, there is the question of how to prioritise the selection of individual improvement principles. In a broad literature review, Reijers and Liman Mansar (2005) identify 29 generic 
principles and their expected impact on process performance. Liman Mansar and Reijers (2007) survey practitioners to identify the 10 most commonly used re-design best practices, but without directly addressing the effectiveness of these practices. In a subsequent study, Liman Mansar et al. (2008) propose the use of the analytic hierarchy process to identify the relative importance and appropriateness of best practices from a list of generic principles. Similarly, Hanafizadeh et al. (2009) develop a method to help organisations select individual best practices of process improvements based on strategic intent and goals. Finally, Barad and Gien (2001) develop a methodology for determining the improvement priorities of small manufacturing companies. This suggests that some redesign principles are likely to be more successful than others for certain redesign efforts. Documenting a list of best practices is useful but does not provide sufficient insights to help managers select among the numerous practices available to them. Additional research is needed to add to this emerging body of literature and determine which improvement principles are more successful relative to other principles. This leads to our first research question:

$R Q 1$ : What are the most and least successful principles of process improvement?

Second, there is limited value in providing an undifferentiated set of redesign practices. Organisations tend to use specific configurations of best practices simultaneously when conducting their improvement initiatives. Liman Mansar et al. (2008) point out that is it important to choose the right combination of best practices to achieve the objectives of the improvement effort. They propose a tool that helps to identify "a set of most appropriate best practices for a specific case" (3249). For instance, 'placing and executing tasks in parallel' may be used in combination with 'increase the number of resources' in order to reduce throughput time (Bruccoleri et al. 2012). Seidmann and Sundararajan (1997) study the simultaneous application of two redesign best practices (i.e. employee empowerment and task combination) using theoretical mathematical models. They find that this combination does not always lead to improved performance. In a similar vein, OM research establishes a number of distinctive archetypes of service and manufacturing systems, which are characterised by specific configurations of process designs. Hayes and Wheelwright (1979) propose a widely-accepted taxonomy of manufacturing processes that are classified into job shops, batches, assembly lines and continuous flow. Each archetype exhibits a unique set of design characteristics that facilitate optimal operational performance. Ponsignon et al. (2011) empirically determine the design characteristics that are appropriate for different types of service delivery processes. These frameworks strongly suggest that there are distinctive operational archetypes that encapsulate different configurations of process design attributes. This fits well with the process improvement literature that suggests that redesign principles are used in combination, rather than individually. Thus, there is the need to establish the configurations of improvement principles which should be applied when redesigning operational processes. This leads to our second research question:

RQ2: What are the major archetypes of process improvement?

In summary, this section has highlighted that the existing evidence regarding the applicability of individual process redesign principles, as well as their combinations, is inconclusive. There is the need to specify the principles that are to be used in priority and the ones that are to be avoided as well as to identify and articulate distinctive organisational archetypes embodying specific patterns of improvement principles. 


\section{Methods}

\subsection{Rationale}

The research questions call for the identification of a method to explore the possible similarities and differences in the success of process improvement principles used by various organisations in order to inform potential archetypes (Tractinsky and Jarvenpaa 1995). We sought a method that can determine successful improvement principles and configurations of principles based on the subjective perceptions of process professionals. Unlike traditional factor analysis, we wanted to group together respondents (rather than variables) who had a similar viewpoint on the subject. We identified Q-Methodology $(\mathrm{Q})$ as a research method that addressed our requirement to emphasise the differences between individual respondents rather than the tradition of concentrating on grouping variables. Watts and Stenner (2012) refer to all statistical methods that use feelings, traits or opinions as variables that are rated by a sample of people as $\mathrm{R}$. The major difference between $\mathrm{Q}$ and $\mathrm{R}$ is that the former aims to reveal patterns of association between the viewpoints of persons about a particular topic whilst the latter purports to identify patterns of association between variables from opinions (e.g. we evaluate customer complaints and we provide dependable products). Accordingly, $\mathrm{R}$ looks to identify latent variables, referred to as factors, which account for manifest associations between opinions. R performs a "by-variable" factor analysis that compares different individuals in relation to traits, opinions or feelings. The statistical procedure isolates those variables whose scores co-vary across a sample of respondents and than can be better understood as "alternative manifestations of a single latent factor" (e.g. supply chain integration). Whilst the foundations of $\mathrm{Q}$ lie in the statistical technique described above, $\mathrm{Q}$ can be thought of as a form of "inverted" factor analysis in so far that it produces a "byperson" factor analysis. Q pursues correlations between respondents in order to identify groups of persons who share a similar perspective about a particular topic. Based on the assumption that the viewpoints, perspectives or attitudes of persons are non-universal, Q captures types that are common to specific groups of people. Whilst $\mathrm{R}$ data is derived from a population of individuals who have been subjected to measurement, $\mathrm{Q}$ data is created by asking respondents to rank-order a sample of heterogeneous items or statements about a topic. Respondents provide their subjective evaluation of a given topic by giving each item a higher or lower ranking relative to the other items. In other words, all items are evaluated relative to each other using a simple dimension such as most-agree/most-disagree. Using a pre-arranged frequency distribution, as illustrated in Figure 1, enables the delineation and standardisation of the ranking procedure. It also facilitates the ascertainment of the degree of agreement and disagreement between entire set of items produced by respondents (i.e. their completed Q-sorts) through the development of a correlation matrix. Factor analysis is then performed on the matrix to generate factors which group together persons who have ranked the items in a similar fashion.

Firstly, Q was used to determine the most and least successful improvement principles among a given set, known as 'concourse'. One of the strengths of $\mathrm{Q}$ is this ability to require respondents to evaluate the principles in terms of their own success as well as in relation to other principles. The Q-sorting process required respondents to rank-order 16 principles (known as 'statements' or 'items') based on their perceptions of relative success in their own organisations. A Q-sort grid with a fixed distribution was used to guide the sorting task. 
Process experts positioned the 16 improvement principles on the grid between -3 (least successful) and +3 (most successful), as shown in Figure 1 .

Secondly, Q is employed to establish groups of experts who perceive similar combinations of successful and unsuccessful principles in their organisations. This facilitates the identification of archetypes, from a population of respondents, comprised of a set of successful and unsuccessful principles that is common to certain organisations and distinct from others (Tractinsky and Jarvenpaa 1995). Q allows for the exploration of patterns and relationships within and between these categories or archetypes (Watts and Stenner 2012). Each category, referred to as a "factor" in Q, embodies a particular approach to process improvement and is identified based on the similarities of the item-ranking across the experts' Q-sorts.

Thirdly, $\mathrm{Q}$ is a hybrid method that extends the quantitative approach using qualitative data, in the form of verbatim comments and open-ended questions about the item-ranking task (see Appendix A), to help interpret and explain patterns found in the data. Comments about why each participant perceived certain principles to be more or less successful than others were collected to aid the interpretation of the statistical results.

$\mathrm{Q}$ has been used in several studies in management research (Wong et al. 2011). More specifically, two studies in OM (Wright and Mechling 2002) and IT management (Tractinsky and Jarvenpaa 1995) share important similarities with this research in that they seek to determine the relative importance of operations problems in small organisations and of IT system design elements, as well as to identify archetypes representing a commonality of viewpoints among experts in these areas. Detailed information about the methodological and statistical aspects of Q-methodology is available from well-established sources (Brown 1980; McKeown and Thomas 1988; Watts and Stenner 2012).

\section{<Insert Figure 1 about here>}

\subsection{Instrument design and validation}

First, items for the Q-sorts were gathered from a synthesis of relevant academic literature (Reijers and Liman Mansar 2005; Ponsignon et al. 2011) and selected through in-depth discussions with eight highly-experienced process practitioners. This helped us to identify a set of statements that is well-balanced, representative and relevant. This process produced a concourse comprising 16 process improvement principles. This purposefully sampled set of items is strongly grounded in extant theory and contains each of the seven broad classes of process improvement identified by Reijers and Liman Mansar (2005). Second, we arranged for five further process professionals to complete a paper-based Q-sort and to provide feedback about the appropriateness, clarity and relevance of each item, as well as about the coherence and representativeness of the whole list. Based on this feedback, several items were reworded. These experts stated that the concourse provided adequate coverage of the diversity of redesign practices used in organisations. Hence, the concourse was deemed to have adequate content validity. The final set of 16 statements and associated descriptions is shown in Table 1. Third, we pre-tested the complete research instrument and the data collection procedure. An online pilot study was carried out with a panel of junior and senior academic researchers $(n=10)$ to validate and fine-tune the web-based Q-sorts. Minor 
suggestions relating to the wording of particular statements and to the questionnaire structure were incorporated into the revised instrument. Feedback from the pilot study also indicated that the whole exercise was quite long and intellectually demanding, which prevented the inclusion of additional items in the concourse. The questionnaire design and the full set of instructions given to the participants are reproduced in Appendix A.

\section{<Insert Table 1 about here>}

\subsection{Data collection procedure}

An online Q-sort was implemented using FlashQ ${ }^{1}$ to obtain populated Q-sorts. Compared to paper-based methods, web-based studies are more convenient and cost-efficient, make it easier to reach respondents, and can be set up faster, coded more easily, and stored electronically.

\subsection{Study participants}

The questionnaire was developed for process experts who represent their respective organisations. The study instructions make it clear that the study focuses on the perceived success of improvement principles in terms of their impact on process performance in the respondents' organisations. Practitioners with significant experience and expertise in process improvement were identified as appropriate respondents and explicitly targeted. Invitations to participate in the web-based study were sent to members of the Process Excellence Network ${ }^{2}$ through their weekly e-newsletter and to members of the LinkedIn Business Process Improvement (BPI) group 3 via the forum's discussion board. Participants had to log onto the secure study Web site to enter their responses. On average, the respondents had 15.3 years of process improvement experience in their organisations $(\mathrm{SD}=8.4)$. Nine industries were represented with banking and insurance, manufacturing, process management consultancies and telecommunications accounting for $77 \%$ of the total number of respondents. The overrepresentation of the financial services industry in the sample (29\%) is in line with reports by Gartner ${ }^{4}$ and Datamonitor ${ }^{5}$ showing significant interest of the banking sector in process management. Similarly, having a slight majority (52\%) of very large companies generating over $\$ 1$ bn in revenues in the sample is not surprising, as process management is more likely to be embraced by large organisations trying to improve sub-optimal units (Smart et al. 2009). The characteristics of the study participants and the organisations they represent are shown in Table 2.

\section{<Insert Table 2 about here>}

We obtained a total of 62 responses, of which we retained 48 for the analysis phase. Results of the pilot study showed that completing the whole exercise with a sufficient level of attention should take at least 25 minutes. First, given the importance of qualitative data to understand and interpret emergent factors, we isolated the 14 participants who did not provide verbatim comments to open-ended questions from the collection of respondents. Basic statistical analysis showed that these 14 respondents took 21 minutes on average to complete the study, whereas the average completion time for the rest of the sample was 49 
minutes. We therefore removed these 14 respondents who completed the Q-sorts in less than 25 minutes and who did not provide comments from the final pool of respondents. 48 respondents is an acceptable sample size for a Q study; leading authorities in Q recommend sample sizes of between 30 and 60 to ensure factor stability (Brown 1980; Stainton Rogers 1995; Watts and Stenner 2005). Previous Q studies in management report samples of 51 and 47 participants (Wright and Mechling 2002; Tractinsky and Jarvenpaa 1995). The requirements for $\mathrm{Q}$ differ significantly from the requirements of representative and large size samples found in traditional quantitative approaches. Traditional statistical techniques require a large number of respondents to study a small number of variables in order to maximise the generasibility of the results to a wider population. In contrast, $Q$ uses respondents as variables and favours studies using small samples of respondents because it simply needs enough participants to establish the existence of factors embodying shared viewpoints (Watts and Stenner 2012). Q does not aim for generasibility; rather it looks to identify archetypes reflecting common perspectives on a topic as well as to understand and compare them.

\subsection{Analysis and interpretation}

Completed grids (i.e. Q-sorts) were correlated with each other (i.e. a by-respondent correlation) and investigated for the presence of factors within the whole dataset. Each extracted factor represents the common viewpoint of a group of process experts that are highly correlated with each other and uncorrelated with other factors, based on the loading of each factor (Watts and Stenner 2005). Here, a factor refers to respondents with similar perceptions about the relative success of the process improvement principles used in their organisations. It represents a unique and holistic configuration of process improvement principles.

The 48 complete q-sorts were analysed using the computer software package PCQ for Windows. First, all Q-sorts were correlated with each other, producing a $48 * 48$ correlation matrix that indicates the degree of similarity between all respondents. The resulting pattern matrix was then rotated using an orthogonal varimax procedure. This generated six factors with an Eigenvalue greater than one. To be considered for full analysis, a factor had to represent the viewpoints of a minimum of four respondents. This is to ensure that sufficient qualitative data in the form of verbatim comments are available to facilitate interpretation of the results. Additionally, each factor had to be clear and unambiguous. As shown in Table 3, the four factors retained for analysis accounted for $48 \%$ of the variance, which is entirely acceptable in Q studies (see for example Tractinsky and Jarvenpaa 1995).

The factor loading of a Q-sort represents the degree to which the respondent correlates with a particular factor. Factor loading determines the significance of a factor, and Q-sorts that load significantly on only one factor are referred to as 'exemplars' (Watts and Stenner 2005). In this study, Q-sorts that have a loading of 0.645 or greater (with $p<0.01$ ) are considered exemplars (see Watts and Stenner 2012, for the mathematical background). Table 3 presents the four factors retained for analysis with their corresponding frequency of exemplars and extent of variance. Q-sorts that load onto the same factor are statistically similar and are clustered. Thus, the seven exemplars of Factor A represent a shared viewpoint about the relative success of the process improvement principles used by the respondents' organisations. To aid interpretation, an 'ideal factor array' is created by merging all the 
exemplars and using a weighted average method in which higher loading exemplars are given more weight in the merger (see Brown 1980; Wright and Mechling 2002). The ideal factor array for each of the four factors is provided in Appendix B.

Interpretation is primarily based on the factor arrays shown in Table 3 and Appendix B. Each factor represents a group of respondents' perceptions about the relative success of the 16 process improvement principles. Our explanation of these factors was informed by items ranked at the extremes (characterising items), by items ranked differently from other factors (distinguishing items) and by items that were similarly ranked across factors (consensus items). Thus, we were able to explore a range of similarities and differences using each of these item categories together with the holistic item configuration in the array. In addition to the statistical sorting we also had access to the open-ended comments provided by respondents in relation to the items placed at the extreme ends of their Q-sorts. Finally, the relevance of emerging patterns was examined in comparison to existing theory.

<Insert Table 3 about here>

\section{Results}

First, we present the results relating to the most and least successful process improvement principles (i.e. RQ1). Second, we discuss the four factors that emerged from the data, which we refer to as archetypes (i.e. RQ2).

\subsection{Analysis of individual process improvement principles}

Three principles are selected for interpretation based on their positions across the four factors and based on how they were ranked by the entire sample of respondents. We limit our analysis to the three principles that highly consensual across respondents. Respondent numbers are referenced to each quote. The remaining principles attracted mixed responses, which suggest that they have different impacts in different situations. A discussion of those principles is outside the scope of this article.

\section{Principle 3: 'Eliminate non-value-adding (NVA) tasks'}

There was broad consensus about this principle. It was ranked as +2 in two factors and as +3 in two other factors (see Table 3). Across the whole sample 28 respondents (58\%) ranked this item as +2 or +3 , while three participants $(6 \%)$ ranked it as -2 or -3 . This indicates that 'eliminate NVA tasks' has been successfully applied by the majority of respondents, while few perceive its use to have been unsuccessful. It is seen as a fundamental improvement principle that is prioritised in process redesign: 'the most important thing and the first step in any improvement initiative' (R3) and 'a foundation of the business' (R29) because it is 'simple and straightforward' (R37) and generates 'very easy wins' (R33). Respondents describe this principle as a customer-centric way of 'streamlining the process' (R12) through waste removal, improving cycle times and achieving efficiency gains through cost reduction and increased throughput. This provides customers with better value for their money. Comments also indicate that this principle is successful in a variety of organisations, including manufacturing, service, private and public companies. Besides this, two respondents indicated the importance of defining value prior to the application of this 
principle ('you need to know what you want to achieve to determine what is value-added' (R7)). Finally, a 'process maturity' (R8) issue was mentioned, possibly indicating that this principle is more effective at the beginning of the process improvement journey. Overall, the data suggest that the 'remove NVA task' principle is generally applicable and that it is the first step in the process improvement journey.

\section{Principle 6: 'Re-sequence tasks'}

Broad consensus about the effectiveness of 're-sequencing' was also achieved. In factors A and $\mathrm{C}$, it was ranked as +2 ; in factors $\mathrm{B}$ and $\mathrm{D}$ it was ranked as +1 (see Table 3 ). Across the whole sample 30 respondents $(63 \%)$ ranked this item as $+1,+2$ or +3 ; while four participants $(8 \%)$ ranked it as -2 or -3 . This suggests that 're-sequence tasks' has been consistently applied with success by a large majority of respondents. Our analysis of the qualitative data suggests that this principle leads to improvements in process productivity through 'optimising the process design' (R36), 'improving flow and eliminating bottlenecks' (R42) and 'reducing costs' (R40). Moreover, it is used 'as part of other initiatives' (R13), or more specifically after 'removing NVA tasks': 'this was next because after removing the non-value-added tasks, then it is possible to re-sequence the tasks' (R4). These comments suggest the existence of a logical pattern where 'remove NVA tasks' and 're-sequence tasks' are used sequentially in the early stages of the improvement journey. Instances where this principle failed to deliver expected benefits were also identified, however: "when we have tried to move process checks upstream nearer to the customer, it has impacted our ability to demonstrate ease of access' (R5). This would suggest that inappropriate tasks were relocated or that there is a conflict between multiple process objectives requiring a trade-off decision between redesign principles. Overall, the data suggest that (1) the 're-sequence tasks' principle is generally applicable; and (2) the 'remove NVA tasks' and 're-sequence tasks' principles are used sequentially.

\section{Principle 10: 'Outsource'}

Outsourcing is perceived as relatively unsuccessful. In factors A and D it was ranked as -2, while it was ranked as 0 and +1 in factors $B$ and $C$, respectively. In addition, across the whole sample, 23 respondents (48\%) ranked outsourcing as -2 or -3 , whilst six participants (13\%) ranked it as +2 or +3 . Proponents of outsourcing mentioned the important cost savings generated by this practice ('returns can be massive' (R19), 'higher efficiency and cost savings' (R47)) as well as the ability for organisations to focus on their core business ('it allows us to focus on what we do best' (R46), 'if you have a process that you're not doing very well and somebody outside does it better than you, then you give it to them' (R19)). However, the cost-effectiveness of outsourcing was questioned by other respondents: 'management overhead was more than expected' (R32), 'the cost of outsourcing is high' (R23), 'so much time, money and effort have been spent in disputes' (R11), 'we have a tendency to outsource what we don't understand, hence we get a high cost' (R1). In addition, an important trade-off between cost and quality emerged where efficiency gains came at a loss of quality, service level and customer satisfaction. 'Cost has been reduced at the expense of quality. Customer satisfaction decreased' (R40); 'short-term financial gain was achieved but perceived service level was reduced' (R35); 'a bean counter would delight in the money 
we've saved, whilst others despair at the poor service' (R13). Other key issues include losing touch with the customer ('nobody likes the outsourced call centre experience. If you're truly customer centric, how you justify mishandling the customer in this way?' (R28); 'our culture is to serve the customer, if we lose contact with the customer, we lose our core competence' (R8)), and culture and mindset problems ('it's cultural, language barrier and problems, it's misunderstanding, it's frustration. It is not the same way of thinking in different cultures, even if the language is the same' (R7); 'they didn't carry our values and didn't represent them in the products' (R20)). The evidence suggests that despite potential cost savings, the effectiveness of outsourcing is questionable.

\subsection{Analysis of process improvement archetypes}

A four factor model accounting for $48 \%$ of the variance emerged from the data suggesting the existence of four distinctive archetypes of process improvement. An archetype represents a shared viewpoint about the principles that are used with the most and least success in the respondents' organisations. Each archetype describes a unique configuration of principles that can be used to redesign an operational process. The ideal configurations of improvement principles for each archetype are represented in Appendix B.

\section{Archetype A: Employee-focused}

Archetype A comprises seven respondents who represent three manufacturing companies and four service organisations. The employee-focused archetype is oriented around improving flexibility through empowered generalist employees, as shown by the positive ranking of the 'empower employees' $(+3)$ and 'use generalists' $(+1)$ principles and by the negative ranking of the 'use specialists' (-3) principle. Other features include maintaining customer contact and resisting automation ('reduce customer contact' (-1) and 'automate' (-2)). The qualitative data also suggests that this archetype relies on a multi-skilled workforce to maintain sufficient flexibility in the process of delivering products and services to the customer. Whilst 'specialisation restricts agility and flexibility' (R42) and 'has resulted in less efficient processes and longer end-to-end times' (R24), generalists provide greater flexibility over available resources and help maintain high levels of utilisation because they 'can be moved to where the work is needed' (R32). In addition, giving decision-making authority to employees helps to 'build ownership and accountability' (R35), to facilitate 'good morale in the workplace' (R32) and 'to get the job done with a sense of pride and commitment' (R22). Consequently, respondents are reluctant to replace employees through automated systems and equipment so as not to 'cripple flexibility and reduce the chances to satisfy a client' (R36). Respondents also commented that the more customer contact, the better. Each customer touchpoint provides an opportunity to understand the customer perspective and to be in a position to fulfil customer requirements ('an opportunity to gain feedback from the customer' (R42), 'the variety of customer needs is too great, we have to maintain a variety of contact channels to meet needs' (R24)). Finally, the use of the generally-applicable 'remove NVA tasks' $(+2)$ is associated with a strong customer focus, rather than solely based on pure internal, efficiency considerations: 'reviewing tasks at hand and seeing the value of process streamlining helped to meet the SLA from the client' (R22). 


\section{Archetype B: Hybrid}

Four respondents from the banking and insurance sector constitute Archetype B. This process improvement approach is distinguished by a propensity to avoid both the reassignment of control tasks to customers (-3) and the reduction of customer contact $(-2)$. The principles of automation (+2) and empowering employees (+3) are also important. Overall, the configuration of principles and comments indicate that this archetype represents a mixed form of process improvement approach characterised simultaneously by customer centricity and a focus on efficiency. The 'hybrid' label highlights the dual goal of managing customer contact activities and non-contact activities to allow the process to focus on different objectives. Customer-centricity is achieved through empowerment, which makes customer contact staff 'interested in customers, sort things out, and handle the variation that occurs in the process' (R7) and that allows 'front-line employees to find small improvements that they can manage themselves' (R37). Appointing a case manager generates 'accountability, somebody responsible for the completeness of the solution' (R7). Moreover, respondents emphasised the need to maintain close customer relationships: 'on the customer-facing side you actually want more customer touchpoints because it becomes a differentiator' (R6); 'the person in charge of the relationship is going to take care of the customer all the way through to implementation' (R7). Improving efficiency by establishing process rigidity is also prevalent. Rigidity is achieved through process automation, the retaining of control and the elimination of unnecessary tasks: 'the only manual task that remains was the reconciliation of input data' (R27); 'you've got to keep some level of control; you don't want to lose control over the decision making process' (R6); 'we eliminated useless jobs, which led to immediate time and cost savings' (R27). Additional evidence for this hybrid conceptualisation includes: 'sales people are the point of contact while other people will be doing the technicalities' (R7) and 'it's very difficult to have a whole case worker; you can have somebody responsible for taking that cradle to grave, but you still require people underneath them to review the claim and handle specific actions and tasks' (R6). Finally, the effectiveness/efficiency duality is exemplified by the complementary role given by respondents to the 'remove NVA tasks' principle: 'I rated this as most important from an efficiency perspective' (R6); and 'by focusing primarily on improving customer service the process becomes more effective, producing higher quality for the customer, whilst reducing costs for the business' (R37).

\section{Archetype C: Cost-focused}

The cost-focused archetype is comprised of five respondents representing one manufacturing organisation and four service firms. This approach is primarily defined by two distinctive improvement principles: not empowering employees (-3) and not using generalists (-2). This suggests that the organisations represented by the respondents rely on specialists who have limited decision-making authority. This is to ensure that employees comply with work procedures and operational guidelines: 'give sales people discretion; they'd use it to get more sales to get larger commissions' (R3); 'staff do not adhere to the defined limits of authority' (R15); 'anything to do with employees is risky; human nature has a tendency not to follow the process' (R3). This suggests that respondents operate in a rigid, relatively inflexible and focused work environment: 'the process is strictly followed' (R21), 'specialised resources ensure complete focus on what they do' (R44). One of the ways to achieve this is to run 
separate processes for separate customers: 'triage is used to separate flow and process different types of customers differently' (R3). Additionally, the role of automation (+1) and process control $(+2)$ is to make the operations error proof through 'automating all the routine tasks' (R44) and 'instigating checking at key points' (R15), which are closely associated with Poka Yoke methods. Finally, 'remove NVA tasks' $(+3)$ and 're-sequence tasks' $(+2)$ principles are associated with a strong focus on productivity optimisation, efficiency gains and cost savings ('improve productivity on the production line' (R21); 'more value for money' (R44); 'save costs and reduce lead time' (R47); 'reduce our workload' (R3); 'efficiency expected through specialised work environment' (R47)).

\section{Archetype D: Workstream-focused}

This archetype represents four service organisations and one manufacturing firm. These organisations require the operational system to adapt to the specific situations they encounter through managing exceptions and establishing separate processes for normal and standard orders or requests. The data acquired for 'manage exceptions' $(+2)$ and 'use of specialists' $(+2)$ corroborate this position. The unique positive ranking of exception management in particular suggests that processes can operate in both standard and exception modes. Performance depends on the ability to define the types of processes more specifically to deal with both modes through organising work, for example, using a triage approach: ' $a$ recognition that we don't want to hold up "normal" work with rarities' (R18); 'we divided customer orders between made-to-order and standard to make sure production and delivery times are adhered to' (R20). This is consistent with a partial 'use of specialists' which 'applies to some areas such as managing key accounts or complaint handling where more specific knowledge is appropriate' (R18). Another respondent commented that 'separating the work into streams allows for better measures of performance and plays to the two types of employees: those that like the "out of the ordinary" tasks and those that view the "out of ordinary" tasks as getting in the way' (R33). A reluctance to implement a variety of process control activities ('Add control tasks' (-3)) is also a distinctive item, which suggests that the initial process design should ensure that 'quality is built into the process' (R2).

\section{Discussion}

\subsection{Implications for theory}

This research makes two important contributions to the process improvement literature (1) by identifying two principles that are perceived as consistently effective and a principle that is relatively ineffective; and (2) by articulating four distinctive improvement archetypes comprising unique configurations of principles that can be used to redesign operational processes. Overall, our findings suggest that process improvement is determined through the application of two foundational principles combined with one of four archetypes.

First, our results strongly suggest that removing NVA tasks and re-sequencing tasks are applicable in most situations, and often used sequentially early on in the improvement journey. Our finding that removing NVA is used to improve both efficiency gains and customer service goes a long way toward explaining why this principle is uniformly effective. This resonates with Reijers and Liman Mansar (2005), who associate this principle with improvements in speed and efficiency, as well as with waste the identification, 
measurement and elimination of waste, which is the basis of lean manufacturing (Pavnaskar et al. 2003). Several lists of wastes in manufacturing and service processes have been produced to assist in identifying non-value adding activities (Pavnaskar et al. 2003). Usually, non-value adding tasks are identified from the end customer's perspective based on customer requirements using, for instance, process models or value stream maps (Braglia et al. 2006). Typical candidates for elimination include control and inspection tasks, which are often performed to solve problems created upstream or verify error-prone outputs generated in previous process steps, as well as redundant tasks, which duplicate resource utilisation without improving quality. Control tasks are often identified by iterations. Buzacott (1996), for instance, shows the quantitative effect of eliminating iterative tasks using a queuing model. Redundant tasks can be identified through assessing the extent of similarity between tasks using, for instance, simple mathematical models (Castano et al., 1999). Another application of this principle can be found in a recent article by Amin and Karim (2013) who provide a methodology for selecting appropriate waste removal techniques to improve the performance of manufacturing processes. Similarly, the literature offers support for the broad applicability of re-sequencing tasks because out-of-sequence tasks are likely to disrupt flow and process execution (Ponsignon et al. 2012). Piercy and Rich (2009) note that ensuring a seamless flow is central to the lean improvement philosophy and has helped to achieve significant improvements in process productivity and efficiency of many organisations. For instance, a large retail bank has moved its credit check activity to the front of its loan application process in order to stop handling credit-unworthy applications which created unnecessary processing costs. Drawing on data collected in 10 process-centric manufacturing and service organisations, Maddern et al. (2013) report that it is essential to understand the often-complex mix of people, materials and information flowing through production processes in order to improve the efficiency and effectiveness of the operational system. These authors emphasise that the focus should shift from an activity-centric perspective to a flow-orientation when undertaking process improvement initiatives. In support of this argument, Yang and $\mathrm{Lu}$ (2011) suggest that maintaining a continuous process flow helps to achieve better service levels and to reduce inventory costs. Their simulation model shows that implementing continuous flow can lead to reductions in inventory of over $57 \%$. We therefore propose that the removal of NVA tasks and the re-sequencing of tasks for flow optimisation are foundational principles of process improvement.

Second, despite the popularity of outsourcing in practice (Handley 2012), which suggests that outsourcing is generally perceived as a positive move for companies (Dekkers 2011), its usefulness for operational improvements is questionable (Jiang and Qureshi 2006). Our findings are broadly in line with a study by Landis et al. (2005) of 50 large IT outsourcing contracts reporting that $44 \%$ of respondents did not obtain the expected level of quality and cost savings and that $64 \%$ brought outsourced services back in-house. While we found some evidence that outsourcing generates cost savings, we found considerably more evidence that challenged the appropriateness of outsourcing. More specifically, the findings emphasise that outsourcing customer-facing processes carries the risk of losing touch with the customer and results in a decrease in service quality and customer satisfaction. A potential explanation for these challenges lie in the inherent variability associated with direct customer interactions (Frei 2007), which introduce uncertainty and complexity in the service process. 
This finding is consistent with a recent study of 205 outsourcing service providers by Narayanan et al. (2011), who report that outsourcing service delivery processes, such as call centres for instance, necessitates achieving high levels of operational integration between the partners in order for the improvement initiative to be successful. We also found that cultural barriers and problems heavily impede the success of outsourcing suggesting that aligning the value systems of different organisations constitute a significant challenge that goes beyond operational and strategic integration issues.

Third, our results establish the existence of four distinct process improvement archetypes. Figure 2 presents a typology of process improvement that displays the pattern of principles characterising each archetype. These findings extend recent developments in the BPM literature suggesting that specific combinations of redesign best practices are appropriate for different types of improvement problems (Liman Mansar et al. 2008). Furthermore, these archetypes can be linked to OM classification schemes that identify distinctive categories of operational systems exhibiting unique configurations of process design characteristics. In particular, there is significant convergence between the 'employeefocused' and 'cost-focused' archetypes and the conceptual model of Buzacott (2000). His classification scheme suggests that all operational processes, including services and manufacturing, should be positioned somewhere along a cost-flexibility diagonal for optimal performance. Our findings provide empirical support for and extend this framework by showing how processes can be redesigned for flexibility or for efficiency. Processes can be made more fluid by transferring decision-making authority to generalist employees and resisting automation, which facilitates the execution of a high variety of tasks. Our data suggests that this approach to process improvement is applicable in both manufacturing and service contexts. More precisely, professional service firms and knowledge-intensive manufacturing firms rely on their human resources as the main source of competitive advantage (Buzacott 2000). This finding is consistent the conceptual model of Hayes and Wheelwright (1979) and the empirical study of Safizadeh et al. (1996), which suggest that "project processes" and "job processes" exhibit similar characteristics and performance drivers to the employee-focused archetype. Conversely, an efficiency-centric improvement approach redesigns processes for a narrow range of activities and relies on high levels of automation and few judgmental decisions by specialists. Again, our data suggests that this approach can be used by both service and manufacturing organisations. More specifically, drawing on previous research, we suggest that a cost-focused improvement approach is likely to be used in the contexts of mass services and service factories (Kellogg and Nie 1995; Silvestro 1999) as well as in mass manufacturing operations (Hayes and Wheelwright 1979) As illustrated in Figure 2, the 'employee-focused' and 'cost-focused' archetypes rely on highly contrasting improvement principles; they can therefore be considered polar opposites. The 'hybrid' archetype, which simultaneously focuses on maximising efficiency gains and maintaining high levels of customer service, resonates with the normative model presented by Chase (1981), inspired by Thompson's (1967) work on minimising the disturbance to the technical core. Chase advocates separating the front office, which is to focus on customers, from the back office, which is to be managed for cost reduction; this approach protects the technical core. Extending these works, Metters and Vargas (2000) empirically derive two distinct process configurations that rely on decoupling customer contact work from non- 
contact activities. The 'cost leader' decouples to lower costs while the 'focused professional' decouples to provide higher service. Our findings provide supportive evidence for the existence of a set of improvement principles for maximising both cost reductions and customer service. The 'hybrid' archetype focuses on the presence of customer contact in the process which is to be split into distinct segments that are improved using different principles. The presence of customer involvement or contact can be found in a variety of service delivery contexts as well as in engineer- or make-to-order manufacturing processes (Hicks and Braiden 2000). Finally, the 'workstream-focused' archetype shares many similarities with the concepts of flexibility, agility and responsiveness. These interrelated terms broadly refer to an organisation's ability to respond to changes in customer demands (Vinodh et al. 2010). The 'workstream-focused' approach makes it possible to handle markedly-different customer requirements (e.g. "normal" and "special" orders or customer requests) by operating separate, focused processes staffed with specialists. The data suggests that this archetype is not directly related to manufacturing or service processes in particular. The provision of clearly distinct types of orders, customers or requests into the production system can be found in a variety of operational contexts as shown by Parnaby (1988) who introduced the concepts of runners, repeaters and strangers for process design. In addition, our results extend the work of Burgess (1994) through specifying the improvement principles that are appropriate to increase the flexibility of operational processes.

In summary, we identified four archetypes of process improvement which can be applied by both manufacturing and service organisations. This is consistent with operations strategy framework emphasising the linkage between volume-variety and process design (Buzacott, 2000; Silvestro 1999). These models postulate that any operation can be classified in terms of its volume-variety mix with broadly similar implications for process design and improvement. In addition, our findings resonate with more recent works suggesting that an organisation's strategic intent and the corresponding value proposition drive process design decisions. In a service context, Ponsignon et al. (2011) provide empirical support for the relationship between the service concept and process design characteristics, as theorised by the service strategy triad of Roth and Menor (2003) and by the service strategy matrix of Kellogg and Nie (1995). Similarly, in a product-centric context, Olhager and Rudberg (2002) suggest the existence of a direct a link between market requirements, product characteristics, and process choice. Maull et al. (2013) empirically show that process design and improvement decisions are more tightly linked to an organisation's value proposition than to the industry or sector in which it competes. These results suggest that understanding the value proposition is more important than any service-manufacturing distinction. Professional services and project-based manufacturing processes offering a highly-customised value proposition should adopt the improvement principles of the employee-focused archetype. Conversely, service factories and mass manufacturing processes offering standardised value propositions should use the improvement principles of the cost-focused archetype. Finally, the fourth archetype, termed 'hybrid', emphasises that process segments devoid of customer contact and segments that handle customer interactions require using distinct improvement principles. 


\subsection{Implications for managers}

Given the plethora of thematic initiatives faced by practitioners, and their continual pursuit of competitiveness, the ability to identify the right combination of principles of process redesign to direct improvement efforts is important. This paper has identified and articulated four distinct approaches to process redesign. Each approach consists of a unique combination of best practices that can be applied to redesign an operational process, with the ultimate choice of either approach depending on organisational requirements and priorities. Rather than adopting generic approaches to improvement, we suggest that managers should consult the improvement typology to select the archetype and the associated principles in closest proximity to their specific requirements. The employee-focused strategy and the cost-focused strategy rely on highly contrasting best practices of redesign. The former requires redesigning fluid processes for flexibility and the execution of a high variety of tasks. Decision-making authority is transferred to employees and automation decisions are to be carefully considered. Organisations considering moving to a low-volume, high-end business model could apply such principles. Consulting and law firms as well as custom manufacturers and R\&D labs are good examples of organisations that fit this archetype. Conversely, the cost-focused archetype concentrates on a narrow range of activities that can be more easily automated. It designs rigid processes for efficiency and where workers make few judgmental decisions. This approach can be used for designing high-volume operations such as mass claims processes or mass manufacturing. The hybrid archetype simultaneously focuses on maximising efficiency gains and maintaining high levels of customer service. This advocates separating the front office, which is to focus on customers, from the back office, which is to be managed for cost reduction. For instance, retail banks often split up the end-to-end service process into distinct front-office and back-office parts, staffing them with different employees and controlling them separately. Finally, the workstream-focused archetype offers the ability to respond to frequent changes in customer requirements by operating separate, focused processes staffed with specialists. Processes redesigned based on this archetype are robust to customer-induced variation. For example, A\&E units separate out patients into 'minors' (i.e. patients who are not seriously ill or injured) and 'majors', and direct them to the appropriate pathways.

Furthermore, the study shows that removing NVA tasks and re-sequencing tasks are widely applicable and independent from the choice of a particular redesign approach. These principles represent the foundations of process improvement, which should concentrate on identifying and eliminating the NVA tasks and on optimising the process flow based on the most natural sequence of execution of the remaining tasks. Finally, our findings suggest that managers should approach outsourcing with caution, especially in the case of customerfacing processes. Letting a third party manage customers seems to be counter-intuitive, as more and more organisations claim to be "customer-centric". Our recommendation is for practitioners to carefully assess the trade-offs associated with outsourcing operational processes. Potential financial returns need to be considered along with cultural and customerproximity issues, which can significantly affect performance in the longer term. 


\subsection{Future work}

Several opportunities exist to build on this work. First, the core findings should be extended through theory testing research. This includes: (1) confirming that 'remove NVA' and 'resequence' tasks are applicable across various organisational contexts and industries and that they are best used sequentially as foundational principles; (2) identifying the antecedents and consequences of outsourcing as well as the domains of application where it is most and least successful. Given the size of the process outsourcing market (estimated to be about $\$ 976$ billion) and its recent yearly growth rate (c. 12\% in 2008) (NASSCOM 2009), such research is important; (3) the four archetypes of process improvement presented here should be explored further and tested for both generalisability and completeness. Second, there is the opportunity to pursue the universality/contingency agenda. Because the practice of process improvement always occurs in a specific context, academic studies need to consider the domain of application of their theories to ensure that they are directly relevant to actual managerial decision-making (Ketokivi 2006). A deeper and more complete understanding of the context in which process improvement takes place and of how context affects success would contribute to the development of more accurate and reliable prescriptions. Follow-up research is needed to examine the conditions under which the individual principles and the archetypes are applicable and result in significant performance improvements. Several contingencies that may affect the success of process improvement could also be studied (e.g. product/service customisation, task-type, strategic intent). The following questions could be addressed: What contextual elements influence the use of improvement principles? How do the task environments, business strategies or other conditions enable or constrain the applicability of specific principles? What is the effect of specific principles and/or of a configuration of principles on process performance? The work of Sousa and Voss (2008) provides valuable sources of ideas and guidelines for researchers interested in pursuing these questions.

\subsection{Limitations}

As with exploratory studies in general, this study has several limitations. First, the number of items populating the concourse is relatively small, which gives participants less freedom with respect to the positioning of the items and therefore affects correlation coefficients. Our approach is nonetheless consistent with previous studies and does not deviate significantly in concourse size (Watts and Stenner 2012; Wright and Mechling 2002). The rationale for including 16 items only was determined during the design of the research instrument which consists of a two-step item-sorting and order-ranking process, six open-ended questions and a six-question-long questionnaire (see Appendix A). This resulted in a relatively timeconsuming exercise. Including more items would have increased the risk of obtaining fewer and less-rigorously completed Q-sorts, as shown in the pilot study. Furthermore, our purposefully sampled set was informed from a synthesis of relevant literature and piloted with academics and practitioners. Feedback showed that it provides adequate coverage of the diversity of redesign practices used in organisations, a key requirement for Q studies with a small number of items (Watts and Stenner 2012). In addition, the experts who participated in the pilot study did not identify important practices that were omitted, which increases our confidence in the concourse's representativeness and adequate coverage of the study domain. 
Second, using a fixed-choice distribution is the standard choice for Q studies. Whilst the characteristics of the distribution affect the study participants, they have virtually no impact on the emerging factors (Brown 1980). Third, there is no claim that the four archetypes are a complete set. The research identifies four distinct approaches to process improvement representing four emerging viewpoints within the practitioner community. Including different redesign principles in the concourse may help to reveal additional process improvement archetypes. Third, implementation problems are not taken into account. Respondents indicated their perceptions of the success of process improvement principles without providing information on the socio-technical challenges they faced. These considerations were beyond the scope of this paper.

\section{Conclusion}

This research makes a relevant and meaningful contribution to our theoretical understanding of process improvement and to managerial practice. It builds on and extends previous work in this area through the identification of two foundational principles and the establishment of four distinctive archetypes of process improvement. Each archetype is comprised of a unique pattern of improvement principles. Given the significance of process improvement in the practitioner community, it is our hope that this area of research will capture the attention of scholars. Further theoretical development, particularly through theory testing and the development of predictive theory, is now required to pursue ways in which process improvement theories can inform practice.

\section{Endnotes}

(1) http://www.qsortonline.com

(2) http://www.processexcellencenetwork.com/

(3) http://www.linkedin.com/groups?home=\&gid=61365\&trk=anet_ug_hm

(4) Front-Office BPM Can Help Your Bank Achieve Customer-Focused Strategy', Gartner brief no.G00126425, 12th April 2005

(5) 'Business process management in European Financial Services', DataMonitor brief BFTC 1039, 07/04

\section{References}

Aldowaisan, T. A., and L. K. Gaafar. 1999. "Business process reengineering: an approach for process mapping." Omega 27 (5): 515-524.

Amin, M. A., and M.A. Karim 2013. "A time-based quantitative approach for selecting lean strategies for manufacturing organisations." International Journal of Production Research 51 (4): 1146-1167

Aurich, J. C., D. Ostermayer, and C. H. Wagenknecht. 2009. "Improvement of manufacturing processes with virtual reality-based CIP workshops." International Journal of Production Research 47 (19): 5297-5309. 
Ayhan, M. B., E. Öztemel, M. E. Aydin, and Y.Yue. 2013. "A quantitative approach for measuring process innovation: a case study in a manufacturing company." International Journal of Production Research 51 (11): 3463-3475.

Auringer, A. 2009. Meeting the Challenge: The 2009 Higher Education CIO Agenda. Stamford, CT: Gartner,

Barad, M., and D. Gien. 2001. "Linking improvement models to manufacturing strategies--a methodology for SMEs and other enterprises." International Journal of Production Research 39 (12): 2675-2695.

Braglia, M., G. Carmignani, and F. Zammori. 2006. "A new value stream mapping approach for complex production systems." International Journal of Production Research 44 (18-19): 3929-3952.

Brown, S. 1980. Political subjectivity: Applications of $Q$ methodology in political science. New Haven, CT: Yale University Press.

Burgess, T. F. 1994. "Making the Leap to Agility: Defining and Achieving Agile Manufacturing through Business Process Redesign and Business Network Redesign." International Journal of Operations \& Production Management 14 (11): 23-34.

Buzacott, J. A. 2000. "Service system structure." International Journal of Production Economics 68 (1): 15-27.

Buzacott, J. A. 1996. "Commonalities in reengineered business processes:models and issues." Management Science 42 (5): 768-782.

Castano S, V. de Antonellis, and M. Melchiori. 1999. "A methodology and tool environment for process and analysis and reengineering." Data \& Knowledge Engineering 31 (3): 253-278.

Chase, R. B. 1981. "The Customer Contact Approach to Services: Theoretical Bases and Practical Extensions." Operations Research 29 (4): 698-706.

Clement, N. 2012. Lessons from Deming for the 21st Century. In Process Perspectives podcast. http://www.processexcellencenetwork.com/organizational-strategies-forinnovation-continuou/podcasts/we-have-a-bewildering-array-of-improvement-tools$\mathrm{w} /$.

Cottyn, J., H. Van Landeghem, K. Stockman, and S. Derammelaere. 2011. "A method to align a manufacturing execution system with Lean objectives." International Journal of Production Research 49 (14): 4397-4413.

Dassisti, M. 2010. "HY-CHANGE: a hybrid methodology for continuous performance improvement of manufacturing processes." International Journal of Production Research 48 (15): 4397-4422.

Davenport, T. 1993. Process Innovation: Reengineering work through information technology. Boston, MA: Harvard Business School Press.

Dekkers, R. 2011. "Impact of strategic decision making for outsourcing on managing manufacturing." International Journal of Operations \& Production Management 31 (9): 935 - 965.

Fowler, A. 2003. "Systems modelling, simulation, and the dynamics of strategy." Journal of Business Research 56 (2): 135-144.

Frei, F. X. 2007. "Breaking the Trade-Off Between Efficiency and Service." Harvard Business Review 85 (3): 93-101.

Greenwood, R., and C. R. Hinings. 1993. Understanding Strategic Change: the Contribution of Archetypes. Academy of Management Journal 36 (5): 1052-1081.

Grover, V., and W. J. Kettinger. 2000. "Business process change in the 21 st century." Business \& Economic Review 46 (2): 14-18.

Hammer, M. 2007. "The Process Audit." Harvard Business Review 85 (4): 111-123. 
Hammer, M., and J. Champy. 1993. Reengineering the Corporation: A manifesto for business Revolution. New York, NY: Harper Business.

Hanafizadeh, P., M. Moosakhani, and J. Bakhshi. 2009. "Selecting the best strategic practices for business process redesign." Business Process Management Journal 15 (4): 609627.

Handley, S. M. 2012. "The perilous effects of capability loss on outsourcing management and performance." Journal of Operations Management 30: 152-165.

Harrington, H. J. 1991. Business Process Improvement - The Breakthrough Strategy for Total Quality, Productivity, and Competitiveness. New York, NY: McGraw-Hill.

Hayes, R. H., and S. C. Wheelwright. 1979. "Link manufacturing process and product life cycles." Harvard Business Review 57 (1): 133-140.

Heskett, J. L., T. O. Jones, G. W. Loveman, W. E. Sasser Jr, and L. A. Schlesinger. 1994. "Putting the Service-Profit Chain to Work." Harvard Business Review 72 (2): 164170.

Hicks, C., and P. M. Braiden. 2000. "Computer-aided production management issues in the engineer-to-order production of complex capital goods explored using a simulation approach." International Journal of Production Research 38 (18): 4783-4810.

Hill, A. V., D. A. Collier, C. M. Froehle, J. C. Goodale, R. D. Metters, and R. Verma. 2002. "Research opportunities in service process design." Journal of Operations Management 20 (2): 189-202.

Ittner, C. D., and D. F. Larcker. 1998. "Are Nonfinancial Measures Leading Indicators of Financial Performance? An Analysis of Customer Satisfaction." Journal of Accounting Research 36 (Studies on Enhancing the Financial Reporting Model ): 135.

Jiang, B., and A. Qureshi. 2006. "Research on outsourcing results: current literature and future opportunities." Management Decision 44 (1): 44 - 55.

Johnston, R., and G. Clark. 2005. Service Operations Management: Improving Service Delivery. 2nd ed. Harlow, England: FT Prentice Hall.

Juan, Y. C., and C. Ou-Yang. 2004. "Systematic approach for the gap analysis of business processes." International Journal of Production Research 42 (7): 1325-1364.

Kellogg, D. L., and W. Nie (1995). "A framework for strategic service management." Journal of Operations Management 13 (4): 323-337.

Ketokivi, M. 2006. "Elaborating the contingency theory of organizations: the case of manufacturing flexibility strategies." Production \& Operations Management 15 (2): 215-228.

Ketokivi, M., and R. Schroeder. 2004. "Strategic, structural contingency and institutional explanations in the adoption of innovative manufacturing practices." Journal of Operations Management 22 (1): 63-89.

Landis, K. M., S. Mishra, and K. Porrello. 2005. Calling a Change in the Outsourcing Market: the Realities for the World's Largest Organizations: Deloitte Consulting.

Liman Mansar, S., and H. A. Reijers. 2007. "Best practices in business process redesign: use and impact." Business Process Management Journal 13 (2): 193-213.

Liman Mansar, S., H. A. Reijers, and F. Ounnar. 2008. "Development of a decision-making strategy to improve the efficiency of BPR." Expert Systems with Applications 36 (2): 3248-3262.

Loch, C. 1998. "Operations Management and Reengineering." European Management Journal 16 (3): 306-317.

Lu, Q., and B. Botha. 2006. "Process development: a theoretical framework." International Journal of Production Research 44 (15): 2977-2996 
Maddern, H., R. Maull, A. Smart, and P. Baker. 2007. "Customer satisfaction and service quality in UK financial services." International Journal of Operations \& Production Management 27 (9): 999-1019.

Madison, D. 2005. Process Mapping, Process Improvement, and Process Management. Chico (CA): Paton Press.

Maull, R., A. Smart, and L. Liang. 2013. "A process model of product service supply chains". Production Planning \& Control 1-16.

McKeown, B., and D. Thomas. 1988. Q Methodology Newbury Park, London: SAGE.

Metters, R., and V. Vargas. 2000. "A typology of de-coupling strategies in mixed services." Journal of Operations Management 18 (6): 663-682.

Narayanan, S., V.Jayaraman, Y. Luo, and J. M. Swaminathan, 2011. "The antecedents of process integration in business process outsourcing and its effect on firm performance." Journal of Operations Management 29 (1-2): 3-16.

NASSCOM. 2009. Strategic Review 2009: The IT Industry in India: National Association for Software and Service Companies.

Olhager, J., and M. Rudberg, 2002. "Linking manufacturing strategy decisions on process choice with manufacturing planning and control systems." International Journal of Production Research 40 (10): 2335-2351.

Parnaby, J. 1988. "A systems approach to the implementation of JIT methodologies in Lucas Industries." International Journal of Production Research 26 (3): 483 - 493.

Pavnaskar S. J., J. K. Gershenson, and A. B. Jambekar 2003. "Classification scheme for lean manufacturing tools." International Journal of Production Research 41 (13): 30753090.

Piercy, N., and N. Rich. 2009. "Lean transformation in the pure service environment: the case of the call service centre." International Journal of Operations \& Production Management 29 (1): 54-76.

Ponsignon, F., P. A. Smart, and R. S. Maull. 2011. "Service delivery system design: characteristics and contingencies." International Journal of Operations \& Production Management 31 (3): 324-349.

. 2012. "Process design principles in service firms: Universal or context dependent? A literature review and new research directions." Total Quality Management \& Business Excellence 23 (11): 1273-1296.

Portioli-Staudacher, A., and M. Tantardini (2012). "A lean-based ORR system for nonrepetitive manufacturing." International Journal of Production Research 50(12): 3257-3273.

Reijers, H. A., and S. Liman Mansar. 2005. "Best practices in business process redesign: an overview and qualitative evaluation of successful redesign heuristics." Omega 33 (4): 283-306.

Rigby, D., and B. Bilodeau. 2005. "The Bain 2005 management tool survey." Strategy and Leadership 33 (4): 4-12.

Roth, A. V., and L. J. Menor (2003). "Insights into service operations management: a research agenda." Production \& Operations Management 12 (2): 145-164.

Safizadeh, M. H., L. P. Ritzman, D. Sharma, and C. Wood. 1996. "An Empirical Analysis of the Product-Process Matrix." Management Science 42 (11): 1576-1591.

Seidmann, A., and A. Sundararajan. 1997. "Competing in Information-Intensive Services: Analyzing the Impact of Task Consolidation and Employee Empowerment." Journal of Management Information Systems 14 (2): 33-56.

Silvestro, R. (1999). "Positioning services along the volume-variety diagonal." International Journal of Operations \& Production Management 19 (3/4): 399-420. 
Slack, N., M. Lewis, and H. Bates. 2004. "The two worlds of operations management research and practice: Can they meet, should they meet?" International Journal of Operations \& Production Management 24 (4): 372-387.

Smart, P. A., H. Maddern, and R. S. Maull. 2009. "Understanding Business Process Management: Implications for Theory and Practice." British Journal of Management 20 (4): 491-507.

Sousa, R., and G. J. C. da Silveira. 2010. "Paradigms of choice in manufacturing strategy: Exploring performance relationships of fit, best practices, and capability-based approaches." International Journal of Operations \& Production Management 30 (12): 1219-1245.

Sousa, R., and C. A. Voss. 2008. "Contingency research in operations management practices." Journal of Operations Management 26 (6): 697-713.

Stainton Rogers, R. 1995. "Q methodology." In Rethinking methods in psychology, edited by J. A. Smith, R. Harre and L. Van Langenhove. London: Sage.

Thompson, J. D. 1967. Organizations in action. New York: McGraw-Hill.

Tractinsky, N., and S. L. Jarvenpaa. 1995. "Information systems design decisions in a global versus domestic context,." MIS Quarterly 19 (4): 507-534.

Ungan, M. 2005. "Management support for the adoption of manufacturing best practices: key factors." International Journal of Production Research 43 (18): 3803-3820.

Vinodh, S., S. R. Devadasan, B. Vasudeva Reddy, and K. Ravichand. 2010. "Agility index measurement using multi-grade fuzzy approach integrated in a 20 criteria agile model." International Journal of Production Research 48 (23): 7159-7176.

Voss, C. A., and C. Huxham. 2004. "Problems, Dilemmas and Promising Practices." Proceedings of the 11th Annual Euroma Conference: 309-318.

Watts, S., and P. Stenner. 2005. "Doing Q methodology: Theory, method and interpretation." Qualitative Research in Psychology (2): 67-91. . 2012. Doing Q Methodological Research. London: Sage.

Wiengarten, F., B. Fynes, E. T. C. Cheng, and R. Chavez. 2013. "Taking an innovative approach to quality practices: exploring the importance of a company's innovativeness on the success of TQM practices." International Journal of Production Research 51 (10): 3055-3074.

Wong, E. M., M. E. Ormiston, and P. E. Tetlock. 2011. "The Effects Of Top Management Team Integrative Complexity And Decentralized Decision Making On Corporate Social Performance." Academy of Management Journal 54 (6): 1207-1228.

Wright, C. M., and G. Mechling. 2002. "The importance of operations management problems in service organizations." Omega 30 (2): 77-87.

Yang, T., and J.-C. Lu. 2011. "The use of a multiple attribute decision-making method and value stream mapping in solving the pacemaker location problem." International Journal of Production Research 49 (10): 2793-2817.

Zairi, M. 1997. "Business process management: a boundaryless approach to modern competitiveness." Business Process Management Journal 3 (1): 64-80. 
1. Reassign control tasks to the customer: this consists of moving control activities (e.g. checks and reconciliation) to the customer. For example, an organisation has redistributed its billing controls to its customers, eliminating the bulk of its billing errors.

2. Reduce customer contact points: his consists of reducing the number of points of contact with customers. For example, ford's accounts payable department decreased the number of customer touchpoints from three to two (resulting in reducing the number of clerks from 500 to 125 ).

3. Eliminate non-value-adding tasks: this consists of eliminating tasks from a business process (e.g. checks and verification tasks through which orders, requests or customers pass).

4. Divide tasks: this consists of dividing large tasks into workable smaller tasks. For instance, implementing triage may involve dividing a task into similar tasks for different subcategories of requests being processed. For example, a special cash desk may be set up for customers with an expected low processing time.

5. Combine tasks: this consists of combining small tasks into composite tasks. For instance, an electronic company compressed responsibilities for the various steps of the order fulfilment process resulting in tasks combined into one task executed by a "customer service representative".

6. Re-sequence tasks (process sequence optimisation): this consists of changing the sequence or order of tasks in a given process. For instance, a retail bank has decided to perform its credit scoring tasks very early in the loan application process.

7. Run tasks in parallel: this consists of configuring a process for the concurrent execution of tasks. It is particularly useful for reducing the cycle time when there is no logical dependency between the tasks.

8. Manage exceptions: this principle consists of designing business processes for typical, standard customer requests or orders and isolating the exceptional ones from the normal flow. For instance, Xerox established a specific procurement process to handle rush orders.

9. Use whole case workers: this consists of letting one employee-type perform as many steps, tasks and activities as possible for single orders, requests or customers. For example, Bell Atlantic assigned a case team to establish high-speed, digital circuits for business customers.

10. Outsource: this consists of outsourcing a business process (or its constituent parts). For instance, some mobile telecommunications organisations have outsourced their call centre operations (i.e. customer service and support) to countries with lower labour costs.

11. Appoint a case manager: this consists of appointing one person to be responsible for handling each type of customer request. The case manager is responsible for a specific order or customer, but is not necessarily the only person who will work on it. The case manager provides a single point of contact for the customer.

12. Make resources more specialised: this consists of turning generalist employees into specialists. A specialist builds up routine more quickly and may have more in-depth and comprehensive knowledge than a generalist.

13. Make resources more generalised: this consists of transforming specialised employees into more generalist employees. For instance, at IBM credit, specialist jobs such as credit checker and pricer were combined into a single position, "deal structurer".

14. Empower employees: this consists of giving employees more decision-making authority. Empowered employees are given the freedom to make decisions without referring to supervisors. For instance, a large telecommunications company has decided 
to allow its top sales managers to change offering specifications to accommodate the needs of high-profile customers.

15. Add control tasks: this consists of adding verification tasks to check the completeness and correctness of incoming materials and/or check the output before it is sent to customers. For instance, a utility company requires high-value bills to be double checked manually before they can be sent to customers.

16. Automate tasks: this consists of replacing employees with automated systems to execute process tasks. For instance, an application of this principle originates with robotics in manufacturing but can be seen in the processing power of enterprise systems such as the deployment of optical character recognition in inputting mass claims.

Table 2: Scores against each item by factor

\begin{tabular}{rlcccc} 
& Factor & $\mathrm{A}$ & $\mathrm{B}$ & $\mathrm{C}$ & $\mathrm{D}$ \\
\hline 1 & Reassign control tasks to the customer & -1 & -3 & -1 & -1 \\
2 & Reduce customer contact points & -1 & -2 & -1 & 0 \\
3 & Eliminate non-value-adding task & 2 & 2 & 3 & 3 \\
4 & Divide tasks & 0 & 1 & 0 & 1 \\
5 & Compose tasks & -1 & -1 & -1 & 0 \\
6 & Re-sequence tasks & 2 & 1 & 2 & 1 \\
7 & Run tasks in parallel & 1 & -2 & 0 & -1 \\
8 & Manage exceptions & 0 & 0 & 0 & 2 \\
9 & Use whole case workers & 0 & -1 & -2 & 0 \\
10 & Outsource & -2 & 0 & 1 & -2 \\
11 & Appoint a case manager & 0 & 1 & 0 & -1 \\
12 & Make resources more specialised & -3 & 0 & 1 & 2 \\
13 & Make resources more generalised & 1 & -1 & -2 & 0 \\
14 & Empower employees & 3 & 3 & -3 & 1 \\
15 & Add control tasks & 1 & 0 & 2 & -3 \\
16 & Automate tasks & -2 & 2 & 1 & -2 \\
\cline { 2 - 6 } & & 7.47 & 4.68 & 5.29 & 5.04 \\
& & $16 \%$ & $10 \%$ & $11 \%$ & $11 \%$ \\
& & 7 & 4 & 5 & 5
\end{tabular}


Table 3: Characteristics of the respondent sample $(n=48)$

\begin{tabular}{|c|c|c|}
\hline Variable & Categories & No. of participants (\%) \\
\hline \multirow[t]{5}{*}{ Revenues } & Less than $\$ 10$ million & $8(17 \%)$ \\
\hline & $\$ 10-\$ 99$ million & $7(15 \%)$ \\
\hline & $\$ 100-\$ 499$ million & $3(6 \%)$ \\
\hline & $\$ 500-\$ 999$ million & $5(10 \%)$ \\
\hline & More than $\$ 1$ billion & $25(52 \%)$ \\
\hline \multirow[t]{5}{*}{ Number of employees } & Less than 100 & $7(15 \%)$ \\
\hline & $100-199$ & $6(13 \%)$ \\
\hline & $1,000-4,999$ & $7(15 \%)$ \\
\hline & $5,000-19,999$ & $8(17 \%)$ \\
\hline & More than 20,000 & $20(42 \%)$ \\
\hline \multirow[t]{9}{*}{ Industry } & Banking and Insurance & $14(29 \%)$ \\
\hline & Telecommunications & $5(10 \%)$ \\
\hline & $\begin{array}{l}\text { Postal, Courier, } \\
\text { Logistics }\end{array}$ & $2(4 \%)$ \\
\hline & Manufacturing & $9(19 \%)$ \\
\hline & BPM Consultancy & $9(19 \%)$ \\
\hline & Public Services & $2(4 \%)$ \\
\hline & Healthcare & $2(4 \%)$ \\
\hline & Professional Services & $4(8 \%)$ \\
\hline & Construction & $1(2 \%)$ \\
\hline
\end{tabular}


Figure 1: Q-sort grid
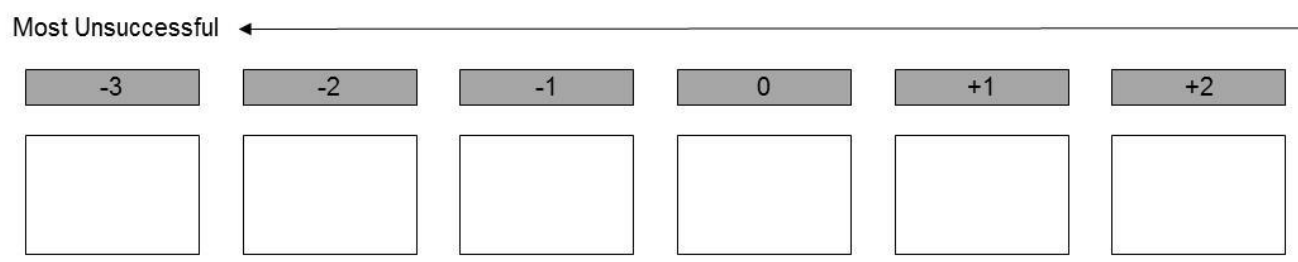

$\rightarrow$ Most Successful
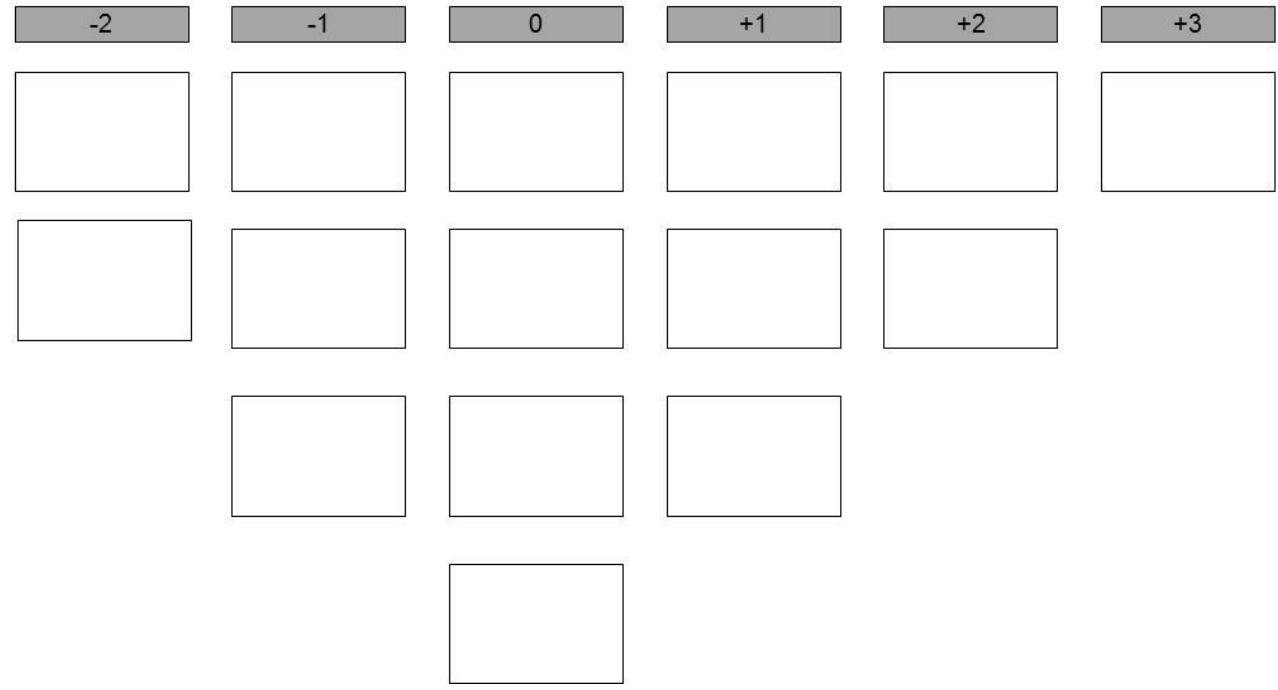

Figure 2: Typology of process improvement

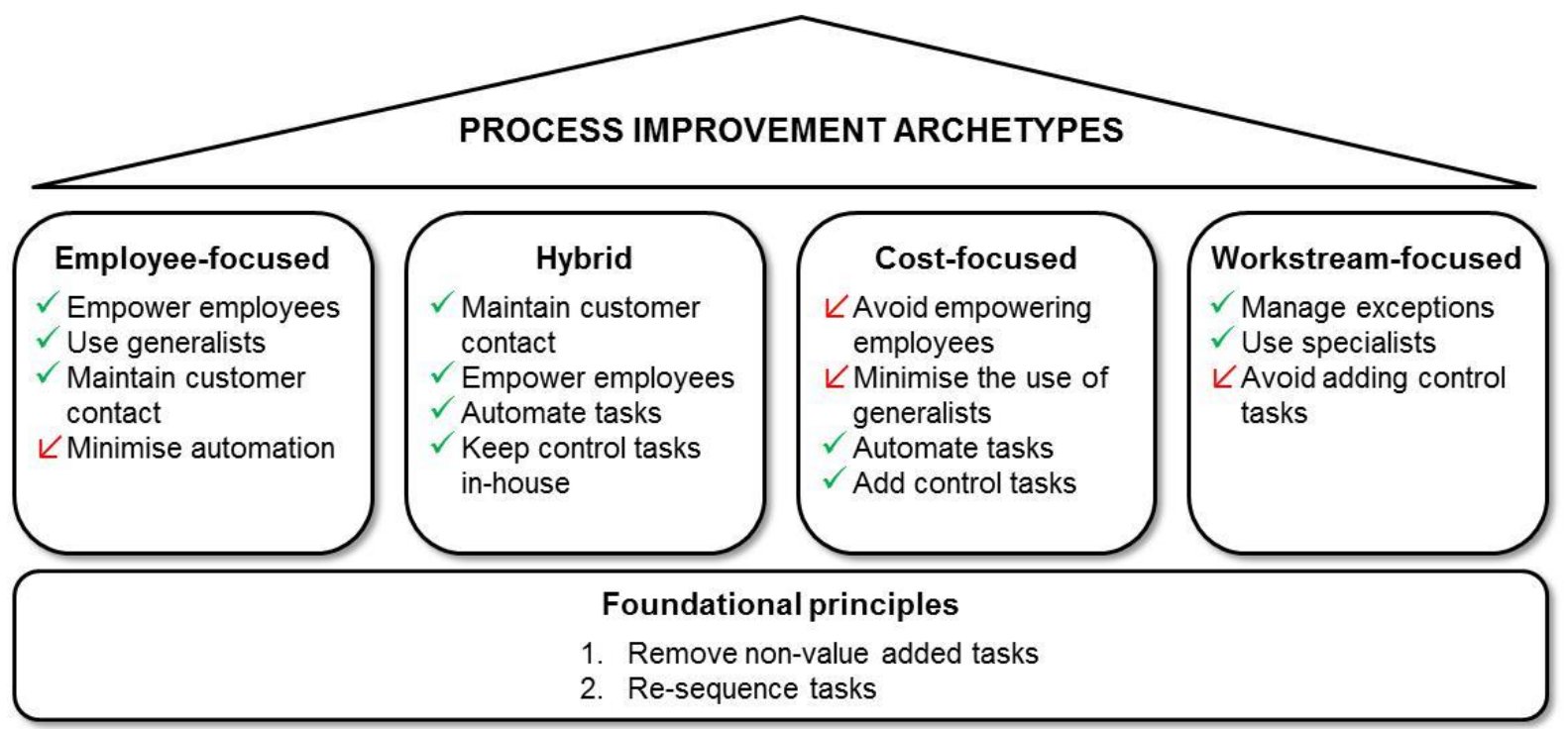




\section{Appendix A - Research instrument and instructions}

Directions

Thank you for your interest in this survey - an assessment of how successful process redesign best practices have been in your organisation. This survey is composed of 4 steps and will take about 30 minutes to complete.

\section{Step 1}

Have these process redesign principles been used successfully at your organisation? Please sort them (by dragging and dropping) into the boxes: 'used successfully'; 'not used successfully'; 'neutral or unused'. We want to know if a particular process redesign principle has improved process performance in your organisation. We are interested in your point of view - so there are no right and wrong answers! Consider a principle successful if it has contributed to improved process performance and its use is effective from a technical perspective. Please read all 16 statements carefully when they appear on the screen.

\section{Step 2}

Rank the process redesign principles by dragging and dropping the principles onto the scoresheet. +3 is the principle you've found most successful and -3 is the one you've found least successful. First, rank the Successful principles in order of most successful $(+3)$ to least. Second, rank the Unsuccessful principles in order of most unsuccessful (-3) to least. Third, place the Neutral or Unused principles in the remaining open boxes of the score sheet. When you have placed all cards on the score sheet, please go over your distribution once more and shift principles if you want to.

\section{Step 3}

Please tell us why you thought these principles were either successful or unsuccessful. [The three principles placed under +2 and +3 and the three principles positioned under -2 and -3 are shown to the participant]

Step 4

Tell us a little bit about yourself

[This section of the questionnaire was designed to collect demographics data about the respondents, as reported in Table 2] 


\section{Appendix B - Ideal configurations of improvement principles}

Figure 3: Archetype A - Employee-focused

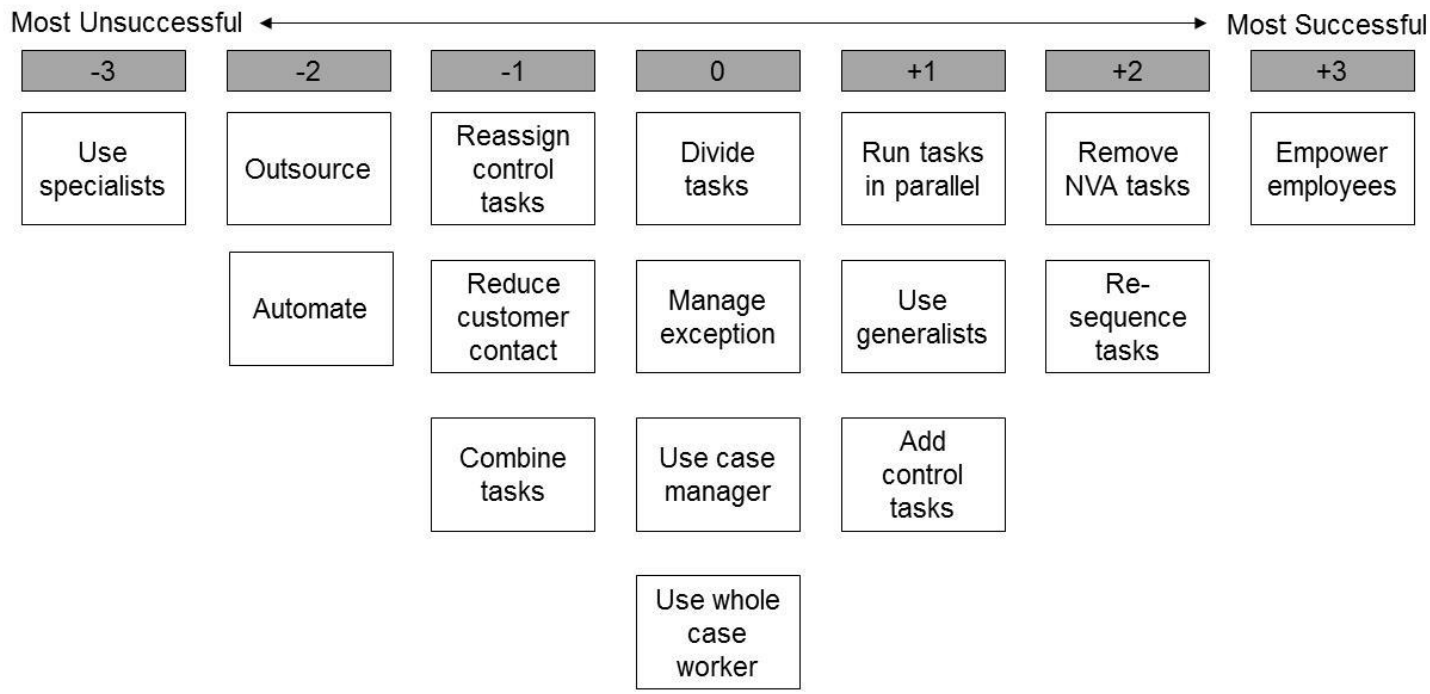

Figure 4: Archetype B - Hybrid

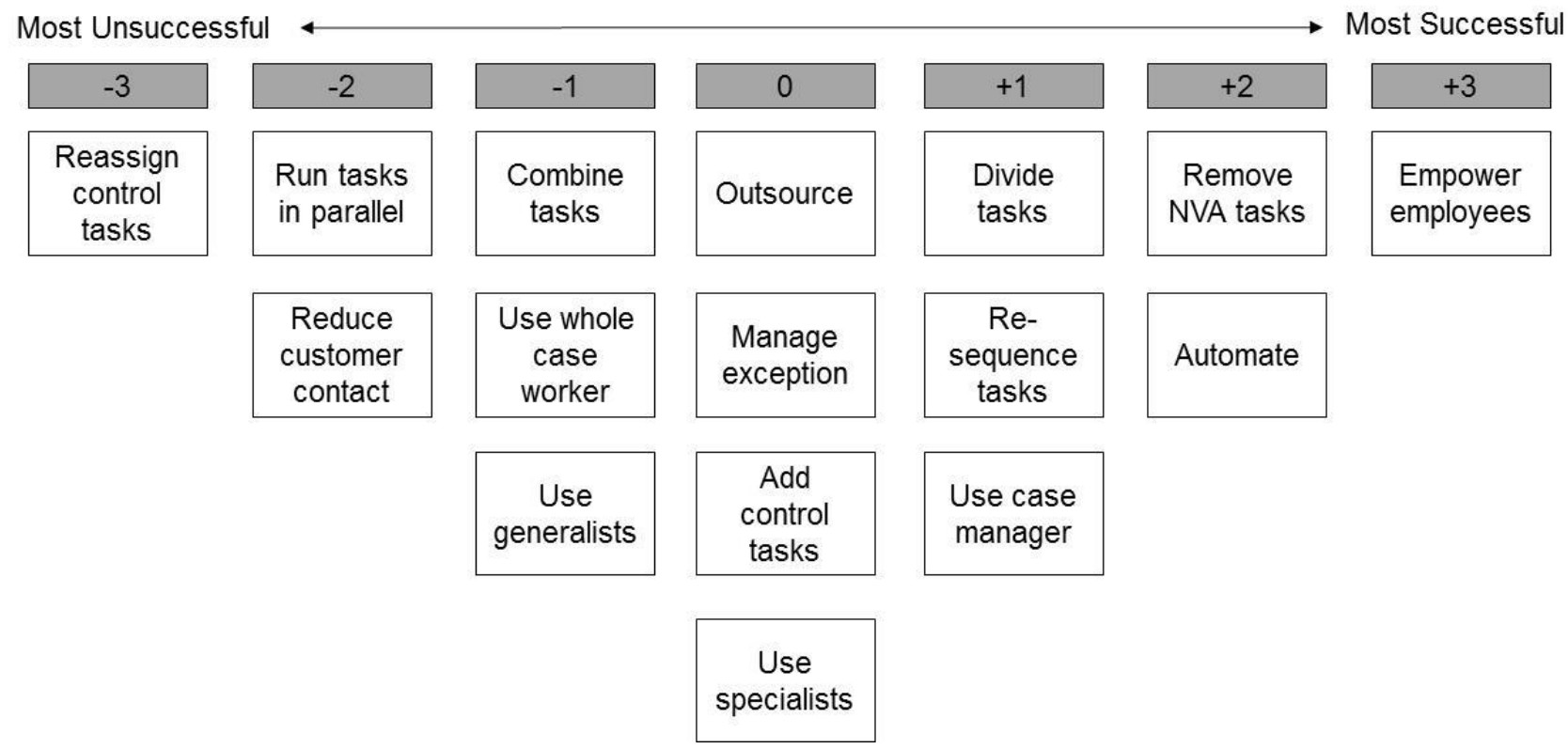


Figure 5: Archetype C - Cost-focused

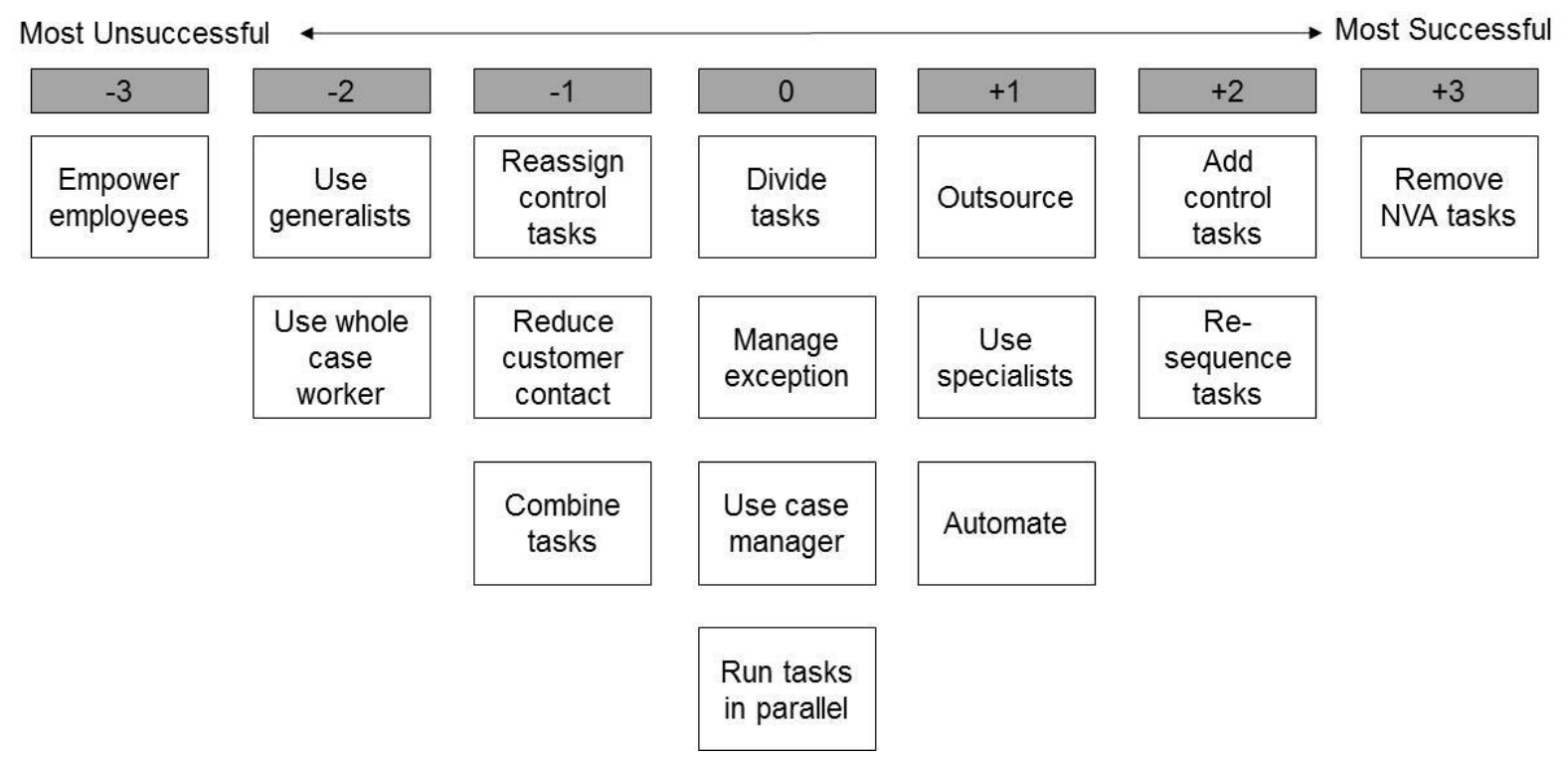

Figure 6: Archetype D - Workstream-focused

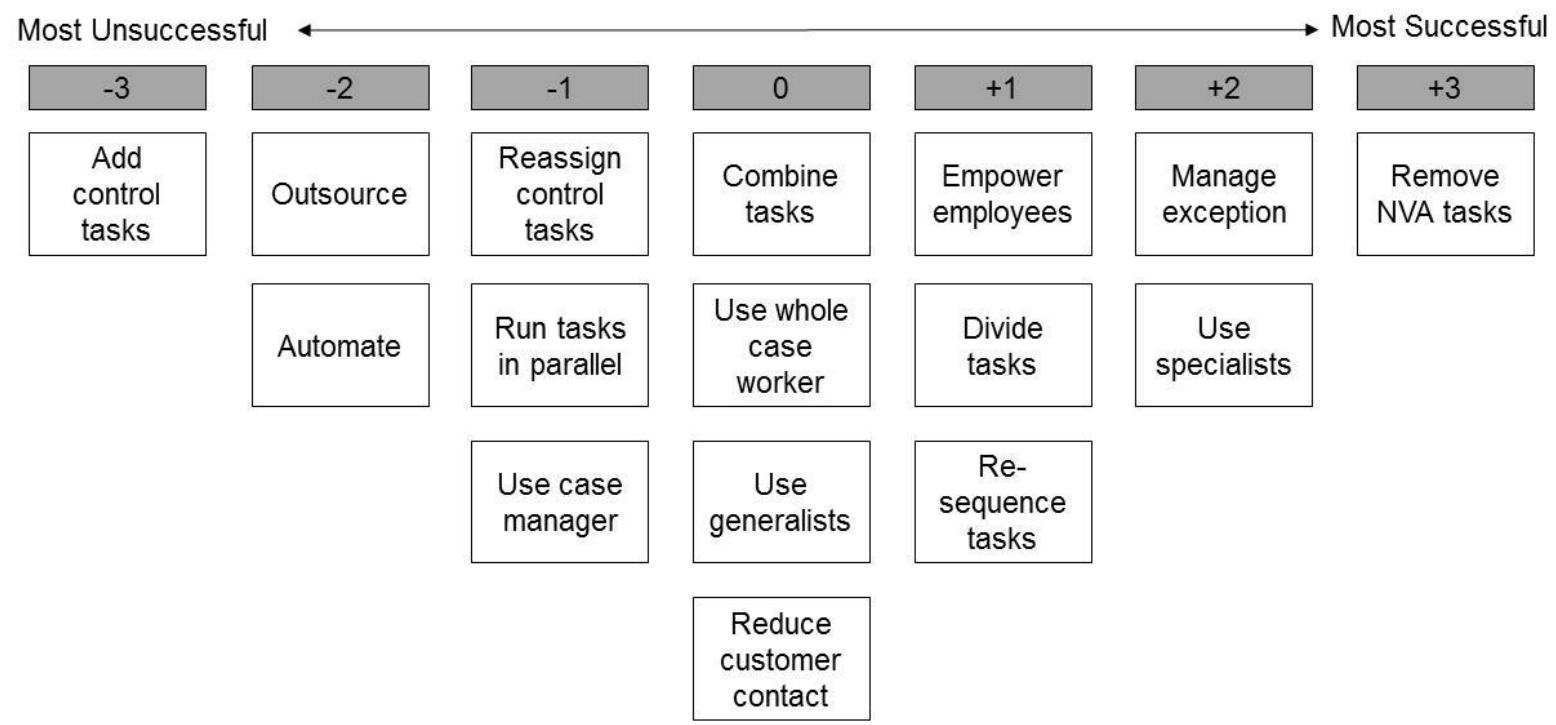

